\title{
The Sky Arrow ERA, an innovative airborne platform to monitor mass, momentum and energy exchange of ecosystems
}

\author{
Beniamino Gioli, Franco Miglietta, Francesco Primo Vaccari, Alessandro Zaldei and Biagio De Martino \\ Istituto di Biometeorologia (IBIMET), CNR, Firenze, Italy
}

\begin{abstract}
Substantial worldwide efforts are underway aimed at identifying the spatial and temporal distribution of the global sources and sinks of atmospheric carbon dioxide $\left(\mathrm{CO}_{2}\right)$. The sink/source strength of vegetated surfaces at ground sites can now be estimated with reasonable accuracy and micrometeorological techniques are now well established, while difficulties exist in up scaling these figures to the regional and global scales. Airborne measurement of mass, momentum, and energy fluxes for boundary layer research has been available for decades requiring the use of large aircraft to carry instruments and dedicated support facilities. The advent of compact, lowpower instruments and high speed, high-capacity digital data acquisition systems has recently allowed small research aircraft to perform such measurements with high accuracy. This paper first describes the Sky Arrow ERA (Environmental Research Aircraft), a small research aircraft that has been recently developed in Italy, in the frame of an international scientific collaboration. This aircraft can be operated to measure fluxes of mass, momentum and energy while flying at low altitude and reduced ground speed. The fluxes are computed with the airborne eddy correlation technique. The basic theory at the basis of the flux measurement technique is also described in the paper, and two application examples are discussed to illustrate the quality and the accuracy of the measurements that can be made using this research platform. Potential applications of those data to parametrize land surface schemes, validate simulation models and provide extensive and reliable ground truthing for satellite remote sensing applications are highlighted.
\end{abstract}

Key words aircraft flux measurements - airborne eddy correlation - terrestrial and marine ecosystems

\section{Introduction}

Research aircraft are becoming increasingly important for biospheric and atmospheric research. Instrumented aerial platforms permit the efficient investigation of problems having

Mailing address: Dr. Beniamino Gioli, Istituto di Biometeorologia (IBIMET), CNR, Via Caproni 8, 50144 Firenze, Italy; e-mail: b.gioli@ibimet.cnr.it spatial distributions ranging vertically well beyond the Planetary Boundary Layer (PBL) and horizontally up to hundreds of kilometers (Bange et al., 2002). Research aircraft can assess the spatial variability of atmospheric properties over relatively large distances in a short period of time, integrating ground observations over large areas. This is of great importance especially for heterogenous surfaces and complex terrains. Until recently, research aircraft were necessarily large to carry heavy power-consuming instruments (Desjardins et al., 1982), but important advancements have been made over the last decade to develop small, fast, and powerful sensors and microprocessors thus making the use of small aircraft for atmospheric re- 
search applications a reality. The recent advent of Small Environmental Research Aircraft (SERA) (Crawford et al., 2001) was of special importance to develop airborne wind and turbulence measurements as small aircraft result in minimized flow distorsion leading to more reliable and precise measurements, and they can fly at low speed and at very low altitude. Moreover SERAs are making airborne science increasingly accessible to a larger scientific community, enhancing the overall capacity to monitor and understand the most important land surface processes and the biosphere/atmosphere interactions and feedback. The European Commission and the European Science Foundation are already favouring such an access through the implementation and management of the European Fleet for Airborne Research (http://www.esf.org/eufar).

This paper provides a technical description of the Sky Arrow ERA (Environmental Research Aircraft), a small research aircraft that has been operated by the Institute of Biometeorology of CNR (National Research Council of Italy) over the last two years. This SERA is the product of an international collaboration between US and Italian scientists and an Italian aircraft industry and it is capable of measuring mass, energy and momentum fluxes using the airborne eddy correlation technique. Two examples of the performance of the Sky Arrow ERA for the measurement of terrestrial and marine/fresh water mass and energy fluxes will also be illustrated and briefly discussed in this paper to highlight the large potential of this innovative tool for environmental research.

\section{Materials and methods}

\subsection{The Sky Arrow ERA}

The Sky Arrow ERA is a small aircraft produced by Iniziative Industriali Italiane (Rome, Italy) equipped with sensors to measure three dimensional wind and turbulence, together with gas concentrations and other atmospheric parameters, at high frequency $(50 \mathrm{~Hz})$. It is a two seater aircraft made of carbon fiber and epoxy resin, powered by a $100 \mathrm{HP}$ engine, with a wingspan of $9.6 \mathrm{~m}$, length of $8.2 \mathrm{~m}$, wing area of $13.1 \mathrm{~m}^{2}$, and a maximum takeoff mass of $648.6 \mathrm{~kg}$. The aircraft has a cruise flight speed of 85 knots with an endurance of $3.5 \mathrm{~h}$, covering flight distances of up to $400 \mathrm{~km}$. Operating altitudes can range from $10 \mathrm{~m}$ above ground level to more than $3500 \mathrm{~m}$ a.s.l. The aircraft is equipped with the Mobile Flux Platform (MFP) which consists of a set of sensors for atmospheric measurements. The Sky Arrow ERA is certified to operate under European and American aeronautical regulations. The SkyArrow engine is mounted in a pusher configuration, allowing the probe being installed directly on the aircraft's nose, minimizing airflow contamination due to upwash and sidewash generated by the wings (Crawford et al., 1996). Atmospheric turbulence measurements are made with the Best Aircraft Turbulence (BAT) probe developed by NOAA-ATDD (National Oceanic and Atmospheric Administration, Atmospheric Turbulence and Diffusion Division) and ARA (Airborne Research Australia). In brief, the BAT probe measures the velocity of air with respect to aircraft, using a hemispherical 9-hole pressure sphere measuring differential pressure caused by different attack and sideslip angles of the wind during motion.

But the measurement of wind velocity with respect to the Earth, $\boldsymbol{V}$, from a moving platform such as an aircraft requires the measurement of two velocity vectors: $\mathbf{V a}$, the velocity of air with respect to the aircraft, and $\boldsymbol{V p}$, the velocity of the aircraft with respect to the Earth. Such three-dimensional velocity vectors are combined as

$$
V=V a+V p
$$

The MFP is designed to correct wind measurements relative to the aircraft that are performed by the BAT probe, for the movement of the aircraft and the sensor with respect to the Earth. Those corrections are made using a combination of GPS (Global Positioning System) velocity measurements and data from two sets of three dimensional accelerometers mounted at the centre of gravity of the aircraft and in the centre of the pressure sphere. For this, a commercial differential GPS (Novatel, U.S.A., 


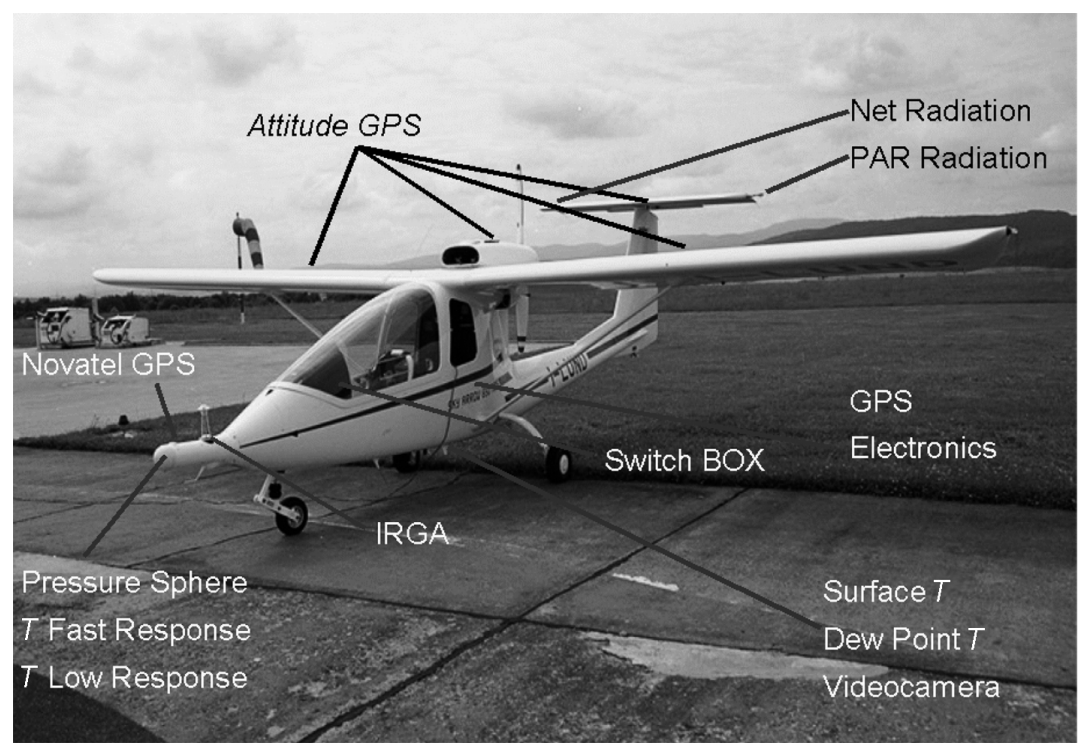

Fig. 1. Photograph of the SkyArrow ERA showing the exact location of the sensors and instruments mounted onboard. The pressure sphere of the BAT probe is visible on the 'nose' of the aircraft.

mod. RT20) is used in combination with a fourantenna vectorial GPS system (Trimble, U.S.A., mod. Tans Vector) to measure three dimensional ground speed and attitude angles up to $10 \mathrm{~Hz}$. A subsequent blending of GPS and accelerometer signals provides attitude and velocity data up to $50 \mathrm{~Hz}$. Accordingly, atmospheric turbulence is measured fifty times per second that translates to a horizontal spacing of $0.7 \mathrm{~m}$ while the aircraft flies at $35 \mathrm{~ms}^{-1}$ ground speed. In this way, eddies of wavelengths larger than $1.4 \mathrm{~m}$ can be resolved. A more complete description of the underlying theory and the technical implementation of airborne wind measurements can be found in Crawford and Dobosy (1992), Dumas et al. (2001).

Scalars are also measured during flight operations. A microbead (thermocouple) temperature sensing element with a nominal time response of $0.02 \mathrm{~s}$ located at the centre of the pressure sphere is used to measure air temperature fluctuations at high frequency. A platinum resistance thermometer is used as a slow response air temperature reference. Atmospheric densities of $\mathrm{CO}_{2}$ and water vapour are recorded at $50 \mathrm{~Hz}$ by an open path infrared gas analyser (Licor, U.S.A., mod. Li7500) installed on the aircraft nose (fig. 1). Low frequency air moisture measurements are made using a chilled mirror dew point sensor (EdgeTech, U.S.A., mod. 200). A net radiometer (Rebs, U.S.A., mod. Q*7) and upward and downward looking PAR radiometers (Licor, U.S.A., mod. $200 \mathrm{~s}$ ) are mounted on the aircraft's horizontal stabilizer. Surface temperature is also measured at low frequency $(1 \mathrm{~Hz})$, using an infrared thermometer (Everest, U.S.A., mod. $4000.4 \mathrm{GH}$ ). All analog signals from the BAT probe (momentum, energy and the scalars) are digitally converted using dedicated AD converters developed by ARA specifically for this type of applications. Once converted to digital signals, the measurements are sent through multi channel serial communication protocols to the on board personal computer, located on the rear of the aircraft. The exact location of the different instruments mounted on board of the Sky Arrow ERA is shown in fig. 1. 


\subsection{Flux measurement technique}

Mass, energy and momentum fluxes are calculated using the conventional eddy correlation technique taking into account all the necessary corrections for open-path gas analyzers (Aubinet et al., 2000). The flux calculation procedure requires the wind components, the air temperature and the concentrations of the species of interest to be sampled at high frequency. The flux $F_{c}$ is expressed as the covariance between the vertical wind component turbulent fluctuation $w^{\prime}$ and the turbulent fluctuation of temperature or the atmospheric mixing ratio of the species of interest $c^{\prime}$

$$
F_{c}=\left\langle w^{\prime} c^{\prime}\right\rangle \text {. }
$$

The angle brackets in eq. (2.2) indicate the appropriate ensemble average.

Airborne and ground-based eddy correlation uses different averaging techniques. It has been found that there is a correlation between vertical air motion and aircraft ground speed, causing some type of turbulent structures being sampled more densely than others (Crawford et al., 1993); this can introduce bias up to $20 \%$ in the fluxes computed simply by using a time average. Hence, turbulent fluctuations of wind vertical component and associated scalars are calculated using means computed over space rather than over time, where space indicates the integral of aircraft ground speed over time. As an example, such «spatial average» is defined for the vertical wind speed $w$, by the following equation:

$$
\bar{w}=\frac{1}{\bar{S} T} \sum_{i} w_{i} S_{i} \Delta t .
$$

Where $S$ is the instantaneous ground speed of the aircraft, $\bar{S}$ is the mean speed, $\Delta t$ is the time increment, and $T$ the total averaging time. Similar averaging procedure is applied to all the variables involved in the covariance calculation.

\subsection{Flux measurements at the regional scale}

One of the most exciting features of flux aircraft such as the Sky Arrow ERA is in their ability to measure surface fluxes at the regional scale. Being versatile in space, but limited in temporal coverage, airborne flux measurements naturally complement those made from fixed towers. The combination of airborne and surface flux measurement was in fact at the basis of the EU-Recab Project (Regional Assessment and Modelling of the carbon balance in Europe, $\mathrm{V}^{\circ}$ EU Research Programme) that investigated regional $\mathrm{CO}_{2}$ fluxes over several regions within Europe during a series of experimental campaigns made both in summer and winter periods in 2001 and 2002. One of those campaigns was performed in The Netherlands in winter 2002 and the results of some of those flights are considered here to illustrate the capabilities and the potential of the Sky Arrow ERA to integrate flux data across spatial scales. In the frame of this particular campaign, two consecutive flights were made in the morning and in the afternoon of 2 February 2002. The duration of each flight was, on average, $2 \mathrm{~h}$ and considered a flight path of approximately $110 \mathrm{~km}$ that was repeated twice. Land use types included a coniferous forest in the northern part of the flight track, wide agriculture land with occasional wetland spots in the southermost part. Flight altitude was around $50 \mathrm{~m}$ above ground. The fluxes of momentum, mass and energy were calculated as described above using a spatial average of $3000 \mathrm{~m}$.

Another campaign performed in winter 2003 has been selected here to illustrate the possibilities offered by the Sky Arrow ERA in measuring fluxes over water bodies, both marine and fresh water. A flight was performed on 17 February 2003 across the the lagoon of Orbetello, Southern Tuscany (Italy). The flight tracks included ten repeated measurements of $\mathrm{CO}_{2}$, sensible and latent heat fluxes that were made at approximately $20 \mathrm{~m}$ above the sea and lagoon surface. Each passage had an average length of $15 \mathrm{~km}$ of which $5+5 \mathrm{~km}$ were over the sea (north and south of the Orbetello lagoon) and $5 \mathrm{~km}$ over the lagoon itself. Spatial averaging for flux determinantion was in this case $2500 \mathrm{~m}$.

\section{Results}

\subsection{Flux measurements over terrestrial ecosystems}

The airborne flux measurement campaigns that were made in the frame of the EU-RECAB 

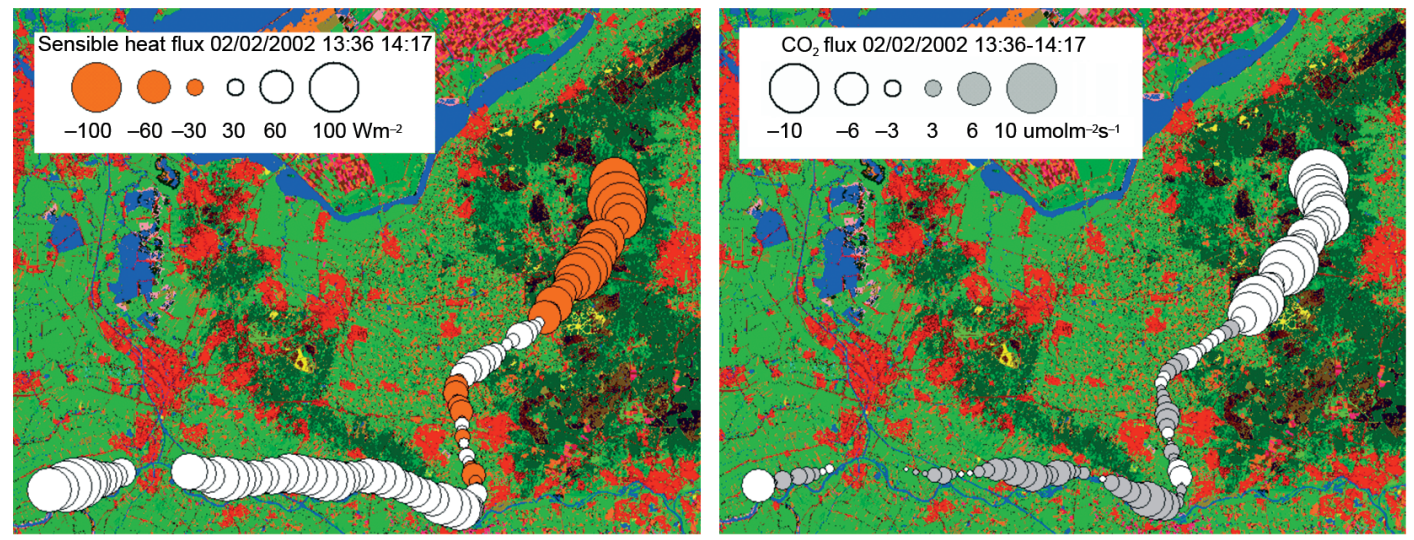

Fig. 2. Sensible heat and $\mathrm{CO}_{2}$ measured fluxes, plotted on land cover map of the region. Bubble diameter is relative to flux magnitude. Dark green patches rapresent forest type ecosystems, light green agricultural type ecosystems, and red urban areas.

project demonstrated, overall, the high reliability of the Sky Arrow ERA as well as the accuracy of the measurements. The results of an extensive comparison between ground-based and airborne fluxes for all the campaigns were excellent and have been reported elsewhere (Gioli et al., 2004). Here, an example of the type of measurements made by the experimental aircraft is given to illustrate its potential application. The most important results obtained during the flights considered here are illustrated in fig. 2. The data reported show that the aircraft was able to discriminate between different land surfaces where different fluxes were measured. Sensible heat fluxes varied from a value of $-80 \mathrm{~W} \mathrm{~m}^{-2}$ over the forested area to $60 \mathrm{~W} \mathrm{~m}^{-2}$ over the agricultural land reflecting the different heat balance properties of the two surfaces. Sensible heat flux was much lower over the forest than over bare agricultural land due in particular to the different albedo, i.e. of the much larger fraction of absorbed radiation by the evergreen foliage compared to bare solis or grasslands. Not surprisingly, $\mathrm{CO}_{2}$ flux also did not differ over the two land uses, with the forest being a small but consistent $\mathrm{CO}_{2}$ sink during the day and the agricultural land being a moderate $\mathrm{CO}_{2}$ source. Scatter in the flux data was greater over the agricultural land reflecting a less homogeneous surface made by a more patchy ecosystem made by a mosaic of different land uses. The data over the forest were instead rather consistent due to a more homogeneous surface. When plotted over the PELCOM land use map (courtesy of Alterra Greenworld, The Netherlands), the flux data showed a consistent spatial pattern reflecting the different land use properties.

\subsection{Flux measurements over the sea and fresh water bodies}

The flights made over and in the proximity of the Orbetello lagoon in Central Italy also provided an illustration of the potentials of the Sky Arrow ERA. During the period of the flight, the surface temperatures of the sea and the fresh water body measured by the infrared thermometer mounted on board of the aircraft were consistently different as a likely consequence of the different depth. The shallow lagoon had an average surface temperature of $277.1^{\circ} \mathrm{K}$ close to an equilibrium with the mean air temperature of $278.8^{\circ} \mathrm{K}$, while the sea had instead a higher surface temperature equal to $284.2^{\circ} \mathrm{K}$. This reflected in highly different latent and sensible heat fluxes, as reported in fig. 3. Latent heat flux ranged from an average of 

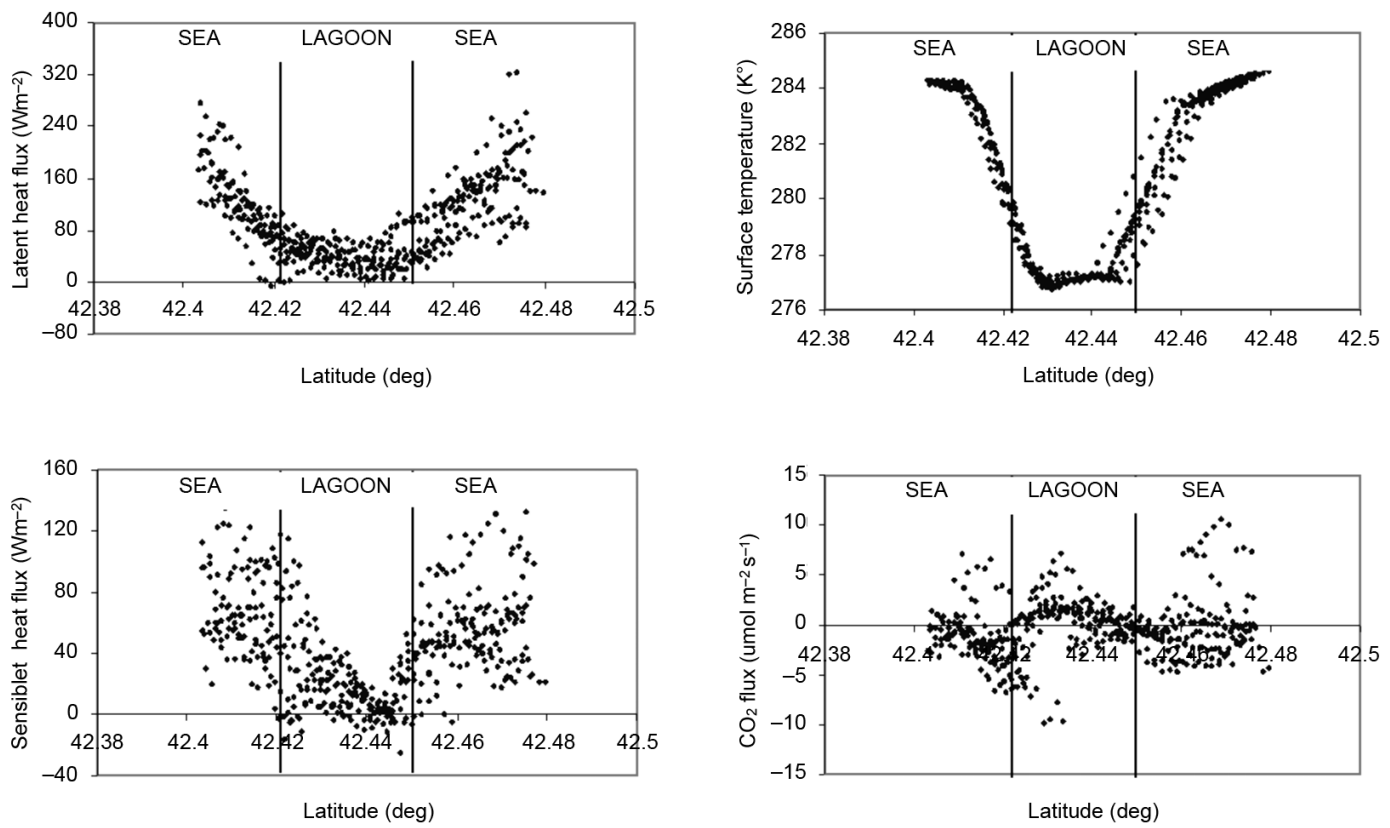

Fig. 3. Sensible heat, latent heat, $\mathrm{CO}_{2}$ fluxes and surface temperature measured over fresh water and marine surfaces, plotted against latitude. Track direction was North-South. Each point is a flux computed over a 2500 $\mathrm{m}$ length path, or, for surface temperature, the average value of the same path. Ten passages over the path are reported. Vertical bars mark the delimitation between marine and lagoon areas.

$20 \mathrm{~W} \mathrm{~m}^{-2}$ over the lagoon area to more than 200 $\mathrm{W} \mathrm{m} \mathrm{m}^{-2}$ over the sea surface, while sensible heat fluxes ranged from almost $0 \mathrm{~W} \mathrm{~m} \mathrm{~m}^{-2}$ over the fresh water body to $120 \mathrm{~W} \mathrm{~m}^{-2}$ over the sea. Flux measurements were also able to capture a small difference in the $\mathrm{CO}_{2}$ uptake of the two surfaces where a small sink was provided by the sea $\left(-2\right.$ umol $\left.\mathrm{m}^{-2} \mathrm{~s}^{-1}\right)$ while the lagoon was, on average, a small source of $\mathrm{CO}_{2}$ with a positive upward flux of $1.6 \mathrm{umol} \mathrm{m} \mathrm{m}^{-2} \mathrm{~s}^{-1}$. This difference possibly reflected unbalanced biological activity in the two water masses or, alternatively, a transient response to progressive warming in the shallow fresh water mass. A mass of water undergoing rapid warming tends to release $\mathrm{CO}_{2}$ in response to temperature-driven degassing. And the lower sensible and latent heat flux of the lagoon water very clearly indicated that the lagoon was absorbing more radiative energy than the sea and this was eventually causing substantial warming of the water mass. This conclusion was further supported by the fact that the surface temperature of the lagoon increased by almost $0.2^{\circ} \mathrm{C}$ over one hour during the flight operations.

\section{Discussion and conclusions}

The results of the two application examples shown in this paper highlight a wide range of potential research applications of the Sky Arrow ERA. Together with other more detailed studies and measurements that have been made in the frame of the EU-RECAB project, those two examples demonstrate that airborne eddy correlation implemented on board of that research aircraft is capable of discriminating with a higher level of detail the fluxes of land surfaces having different properties and different land use. While extrapolated to entire regions, these measurements offer an extraordinary opportuni- 
ty to understand the dynamics and the spatial variability of heat flux, evaporative flux, and $\mathrm{CO}_{2}$ sources and sinks. Such information is of utmost importance to derive land parameterization schemes, validate simulation models and provide extensive and reliable ground truthing for satellite remote sensing applications.

The direct parameterization of land surface properties provides, for instance, a solid basis to map carbon sources and sinks of a given region and even entire countries. The overall uptake of $\mathrm{CO}_{2}$ by forests or agricultural crops is, in turn, a measure of the potential terrestrial Gross Primary Production (GPP) and, to some extent, of the distribution of the potential terrestrial Carbon sink. Flux data measured at regional scale also provide valuable input data for surface-coupled atmospheric meso-scale models that are eventually able to calculate atmospheric mixing and the concentration of scalars and temperature in the planetary boundary layer.

Airborne measured fluxes and the direct measurement of wind speed and direction and atmospheric turbulence are excellent tools for the validation of a series of simulation models. $\mathrm{CO}_{2}$ fluxes provide validation data for soil-vegetation-atmosphere transfer models or more deterministic ecological models that can calculate the overall exchange of carbon dioxide occurring between the terrestrial ecosystem and the atmosphere. Once sea surface fluxes are measured, airborne flux data can also provide a validation basis for marine and oceanographic models trying to simulate the effect of the environment on the overall exchange of mass and energy between the ocean and the atmosphere. In addition, atmospheric turbulence and momentum fluxes that can be directly measured with research aircraft over the sea can provide valuable data to validate models attempting to calculate the drag and the source of turbulent kinetic energy of the waves under the different synoptic wind conditions.

Finally, the data provided by aircraft platforms like the Sky Arrow ERA are a unique resource for an extensive validation of a series of satellite remote sensing products as, for instance, the MODIS GPP estimate (Reeves et al., 2002) that is routinely available to the users and that is one of the most promising tools to esti- mate the global Carbon sink of the terrestrial biosphere.

The overall affordability of SERAs in general and in particular of the Sky Arrow ERA is capable of further enhancing the value of the data that can be obtained while opening access to advanced airborne research to a much wider research community in the near future.

\section{Acknowledgements}

The results shown in this paper contribute to the RECAB project funded by the $\mathrm{V}^{\circ}$ Framework Programme of the Commission of the European Union (Contract EVK2-1999-00034). The authors wish also to acknowledge the valuable contribution of Captain Paolo Amico of AvioRoma srl, the pilot of the Sky Arrow ERA, Ronald Hutjes (Alterra Greenworld, Wageningen, NL) and Edward Dumas (NOAA-ATDD). This paper is dedicated to Tim Crawford (NOAA-ARL) and Furio Lauri (Iniziative Industriali Italiane SpA) who passed away while this work was ongoing.

\section{REFERENCES}

Aubinet, M., A. Grelle, A. Ibrom, Ü. Rannik, J. MonCriefF, T. FoKen, A.S. Kowalski, P.H. Martin, P. Berbigier, C. Bernhofer, R.Clement, J. Elbers, A. Granier, T. Grünwald, K. Morgenstern, K. PileGAARD, C. REBMANN, W. SNiJders, R. VALENTINI and T. VESALA (2000): Estimates of the annual net carbon and water exchange of European forests: the EUROFLUX methodology, Adv. Ecol. Res. 30, 113-175.

Bange, I., F. Beyrich and D.A.M. Engelbart (2002): Airborne measurements of turbulent fluxes during LITFASS-98: Comparison with ground measurements and remote sensing in a case study, Theor. Appl. Climatol., 73 (1-2), 35-51.

Crawford, T.L. and R.J. Dobosy (1992): A sensitive fast response probe to measure turbulence and heat flux from any airplane, Boundary-Layer Meteorol., 59, 257-278.

Crawford, T.L., R.T. McMillen, R.J. Dobosy and I. MACPHERSON (1993): Correcting airborne flux measurements for aircraft speed variation, Boundary-Layer Meteorol., 66, 237-245.

Crawford, T. L., R.J. Dobosy and E.J. Dumas (1996): Aircraft wind measurement considering lift-induced upwash and large attack angles, Boundary-Layer Meteorol., 80, 79-94.

Crawford, T.L., G.H. Crescenti and J.M. Hacker (2001): Small Environmental Research Aircraft (SERA): the 
future of airborne geoscience, in Eleventh Symposium on Meteorological Observations and Instrumentation, Albuquerque, NM, Am. Meteorol. Soc.

Desjardins, R.L., E.J. Brach, P. Alno and P.H. SchuepP (1982): Aircraft monitoring of surface carbon dioxide exchange, Science, 216, 733-735.

Desjardins, R.L., J.I. MacPherson, P.H. SchuepP and F. KARANJI (1989): An evaluation of aircraft measurements of $\mathrm{CO}_{2}$, water vapour and sensible heat, Boundary-Layer Meteorol., 47, 55-69.

Dumas, E.J., S.B. Brooks and J. Verfaillie (2001): Development and testing of a Sky Arrow 650 ERA for atmos- pheric research, in Eleventh Symposium on Meteorological Observations and Instrumentation, Albuquerque, NM, Am. Meteorol. Soc.

Gioli B., F. Miglietta, B. De Martino, R.W.A. Hutjes, A.J. Dolman, A. Lindroth, M. Schumacher, M.J. SANZ, G. Manca, A. Peressotti and E.J. Dumas (2004): Comparison between tower and aircraft-based eddy covariance fluxes in five European regions, Agric. For. Meteorol., 127 (1-2), 1-16.

ReEves, M.C., J.C. Winslow and S.W. RunNing (2001): Mapping weekly rangeland vegetation productivity using MODIS algorithms, J. Range Manage., 54, A90-A105. 